\title{
Evaluation of Salivary Leptin Levels and Its Correlation with Class I, Class II, and Class III Facial Skeletal Pattern: A Prefatory Study
}

\author{
Danusha Siva Dharma ${ }^{1}$ Noraini Abu Bakar ${ }^{2}$ Basma Ezzat Mustafa ${ }^{3}$
}

${ }^{1}$ Department of Bioscience, Kulliyyah of Science, International Islamic University Malaysia, Pahang, Malaysia

${ }^{2}$ Department of Orthodontics, Kulliyyah of Dentistry, International Islamic University Malaysia, Pahang, Malaysia

${ }^{3}$ Department of Fundamental Dental and Medical Sciences, Kulliyyah of Dentistry, International Islamic University Malaysia, Pahang, Malaysia

Eur J Dent 2021;15:647-652.
Address for correspondence Noraini Abu Bakar, Department of Orthodontics, Kulliyyah of Dentistry, International Islamic University Malaysia, 25200 Kuantan Campus, Pahang, Malaysia (e-mail: nor_aini@iium.edu.my).

\author{
Abstract \\ Keywords \\ - salivary leptin \\ hormone \\ - facial skeletal pattern \\ - dental malocclusion
}

Objective The aim of this study was to assess and compare the salivary leptin hormone levels between different classes of facial skeletal pattern (Class I, II, and III).

Materials and Methods A sample of 62 patients were selected prior to the orthodontic treatment from a population that attended the International Islamic University Malaysia Specialist Orthodontic Clinic. Based on the lateral cephalometric analysis, the subjects were grouped into Class I, Class II, and Class III facial skeletal patterns, according to Eastman and Wits appraisal. Subsequently, unstimulated saliva samples were taken and purified to undergo leptin enzyme-linked immunosorbent assay analysis to determine the levels of leptin hormone. Statistical analysis using the Kruskal-Wallis test was used to analyze the data obtained.

Results The results showed that there was a significant difference between the levels of leptin hormone between Class I and Class II skeletal patterns and between Class I and Class III facial skeletal patterns. No statistical difference was noted between the levels of leptin of Class II and Class III facial skeletal patterns.

Conclusion Salivary leptin hormone levels are higher in patients with Class II and Class III facial skeletal patterns compared with Class I.

\section{Introduction}

Leptin is an adipose-derived protein secreted by adipocytes and is expressed in adipose tissue. ${ }^{1}$ It has the role of being a key regulator of several physiological pathways including body weight and regulation of food intake, inflammation, endocrine function, energy homeostasis, bone metabolism and immunity. ${ }^{2}$ Results from various studies indicate that leptin may play a significant role in bone physiology, independent of the central nervous system. ${ }^{4}$

published online August 24, 2021
DOI https://doi.org/ $10.1055 / \mathrm{s}-0041-1727552$ ISSN 1305-7456
Leptin also acts as a cytokine that is involved in the process of inflammation whereby it upregulates the secretion of multiple inflammatory cytokines including tumor necrosis factor- $\alpha$, interleukin (IL)-6, and IL-12. ${ }^{5}$ It has also been shown that in patients with chronic periodontitis, leptin concentrations in saliva and serum are significantly altered. ${ }^{6}$

Leptin also impacts bone metabolism through direct and indirect mechanisms. ${ }^{7}$ It has been reported that there is a direct osteogenic effect of leptin on human bone marrow stromal cells, enhancing osteoblastic differentiation by

(c) 2021. European Journal of Dentistry.

This is an open access article published by Thieme under the terms of the Creative Commons Attribution-NonDerivative-NonCommercial-License, permitting copying and reproduction so long as the original work is given appropriate credit. Contents may not be used for commercial purposes, or adapted, remixed, transformed or built upon. (https://creativecommons.org/licenses/by-nc-nd/4.0/)

Thieme Medical and Scientific Publishers Pvt. Ltd., A-12, 2nd Floor, Sector 2, Noida-201301 UP, India 
promoting the expression of genes related to bone differentiation. ${ }^{8}$ Results from a recent study by Zhang et al ${ }^{9}$ suggest that leptin may also enhance osteogenesis by cross-regulating BMP9 signaling through the JAK/STAT signaling pathway in mesenchymal stem cells. A study by Holloway et al in $2002^{10}$ showed that leptin inhibits osteoclast generation and bone resorption. These results indicate that leptin may act as a potentiator for skeletal growth.

With regards to leptin in orthodontics, a preliminary study done by Bakar et al, ${ }^{11}$ concluded that leptin concentration in saliva is decreased during orthodontic tooth movement in initial alignment stage and that leptin may be one of the mediators associated with orthodontic tooth movement.

Other than that, in a study done by Yan et al, ${ }^{12}$ found that orthodontic tooth movement was attenuated in obese mice with elevated levels of leptin via the inhibition of osteoclastogenesis. Clinical implications of this include prolonged treatment times for patients with a higher body mass index (BMI).

A recent study also concluded that the mean gingival crevicular fluid (GCF) leptin concentration during orthodontic force application initially showed an increase in levels followed by a decrease after 1 week and reaching a concentration lesser than the base line value after 1 month. It was concluded that there was an overall strong positive correlation between the mean GCF leptin concentration and the rate of tooth movement. ${ }^{13}$

To date, no studies were found investigating the levels of leptin hormone in various classes of skeletal pattern prior to orthodontic treatment. There have been studies that have looked into the leptin hormone and how it affects orthodontic tooth movement. ${ }^{11}$ It would be useful to know if this hormone differs in various classes of facial skeletal pattern prior to orthodontic treatment and we aim to address that in this prefatory study.

\section{Objectives}

This study aimed to determine levels of salivary leptin hormone in patients with Class I, II, and III skeletal patterns and compare the levels of salivary leptin hormone between Class I, II, and III skeletal patterns.

\section{Materials and Methods}

\section{Study Design}

This study takes a quantitative approach and is of a cross-sectional design and used convenience sampling as the sampling method. The target population was the prospective active orthodontic patients from the Orthodontic Department, Kulliyyah of Dentistry, International Islamic University Malaysia (IIUM).

\section{Patient Selection}

The subjects were active orthodontic patients from the Orthodontic Specialist Clinic, Kulliyyah of Dentistry, IIUM.
The assessment of eligible subjects involved clinical examination and review of subjects' clinical and radiographical records. Clinical record assessment includes a combination of study models, cephalometric tracings, and photographs. Eastman and Wits cephalometric analyses were performed.

This prefatory study involved a total of 62 patients, whereby 24 subjects from a control Class I skeletal pattern (15 female and 9 male), 23 subjects from a Class II skeletal pattern ( 12 female and 11 male), and 15 subjects from a Class III skeletal pattern ( 8 female and 7 male). The subject's selections were based on the criteria given as follows:

\section{Inclusion Criteria}

- Good health.

- Normal BMI, according to the World Health Organization chart (BMI of 18.5-22.9).

- No history of the use of anti-inflammatory drugs within the month preceding the sample collection.

- No history of the use of antimicrobial therapy within the previous 6 months.

- Healthy periodontal tissues with generalized probing depths of $\leq 2 \mathrm{~mm}$, with minimal bleeding and no sign of attachment loss.

- No radiographic evidence of periodontal bone loss.

\section{Exclusion Criteria}

- Craniofacial deformity including cleft lip and palate.

- Endocrinological disease including those with diabetes.

- Anomalies in tooth number, morphology, and eruption.

\section{Cephalometric Analysis}

Identified subjects underwent comprehensive clinical examination by one of the researchers at IIUM Specialist Clinic to ensure no anomalies in tooth number, morphology, and eruption. A lateral cephalometric radiograph was taken as a record for cephalometric analysis. Eastman analysis, ${ }^{14}$ measuring sella-nasion-A-point angle (SNA), sella-nasion-B point angle (SNB), A point-nasion-B point (ANB), and the Wits appraisal (AoBo) were executed. ${ }^{15}$ The points as illustrated in - Fig. 1.

SNA angle was used to assess the position of maxilla to cranial base while SNB angle was used to determine the position of mandible to the cranial base. The ANB angle, which has been recognized as the most commonly used anteroposterior skeletal discrepancy indicator ${ }^{16}$ was then calculated. It compares the relationship of the maxilla and the mandible with regards to the cranial base. The classification used denotes that a 2- to 4-degree value indicates a Class I malocclusion, above 4 degrees indicates a Class II malocclusion, and below 2 degrees is indication for a Class III malocclusion. ${ }^{17}$

The Wits appraisal, which compares the relationship of the maxilla and the mandible with regards to the functional occlusal plane (FOP) was used to further confirm the anteroposterior occlusal disharmony. A line is drawn between the cusp tips of the molars and premolars and this is known as the FOP. A perpendicular line is drawn from point $A$ and point $B$ to the FOP to give points $\mathrm{AO}$ and $\mathrm{BO}$. The distance between $\mathrm{AO}$ and $\mathrm{BO}$ is measured. The average (Class I malocclusion) values are- $1 \mathrm{~mm}$ 


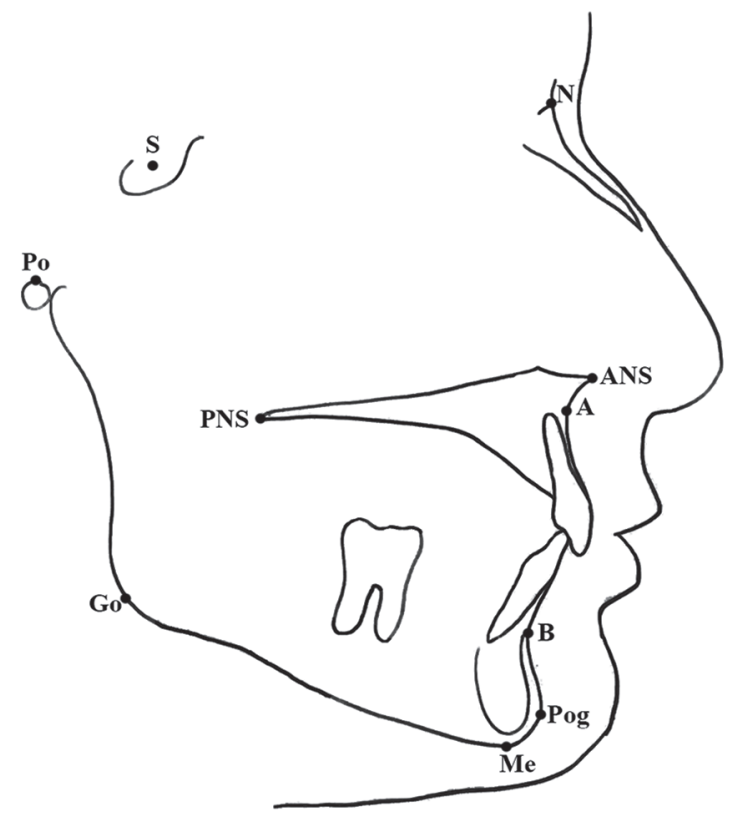

Fig. 1 Reference points on the cephalometric radiograph: Sella (S) midpoint of the sella turcica, nasion (N), A point (A) - deepest point of concavity on the anterior profile of the maxilla, $B$ point (B) - deepest point of concavity on the anterior surface of the mandibular symphysis, gonion (Go) - the most posterior, inferior point on the angle of the mandible, menton (Me) - the most inferior point on the mandibular symphysis, pogonion (Pog) - the most anterior point of the mandibular symphysis, porion ( $\mathrm{Po}$ ) - the upper midpoint of the external auditory meatus, anterior nasal spine (ANS), and posterior nasal spine (PNS).

$( \pm 1.9 \mathrm{~mm})$ for males and $0 \mathrm{~mm}( \pm 1.77 \mathrm{~mm})$ for females. ${ }^{17}$ Values below the average values denote a Class II malocclusion and values above the average denote a Class III malocclusion.

Subjects were grouped into facial classes based on the analysis criteria below.

\section{Cephalometric Analysis Criteria for Class I Facial Skeletal Pattern}

1. Cephalometric value indicative of Class I based on Eastman (ANB within 2 to 4 degrees, SNA within range of $81 \pm 3$ degrees, and SNB within range of $78 \pm 3$ degrees) as shown in - Fig. 2.

2. Wits appraisal (AoBo) within Class $\mathrm{I}(-2 \mathrm{~mm}$ to $+2 \mathrm{~mm})$.

3. Straight facial profile.

\section{Cephalometric Analysis Criteria for Class II Facial Skeletal Pattern}

- Cephalometric analysis with value indicative of Class II based on Eastman analysis (ANB should be $>4$ degrees and SNB should be $<78$ degrees) as shown in - Fig. 3.

- SNA within normal range indicative of average maxilla ( $81 \pm 3$ degrees).

- Positive Wits appraisal (AoBo $>2 \mathrm{~mm}$ ).

- Convex facial profile.
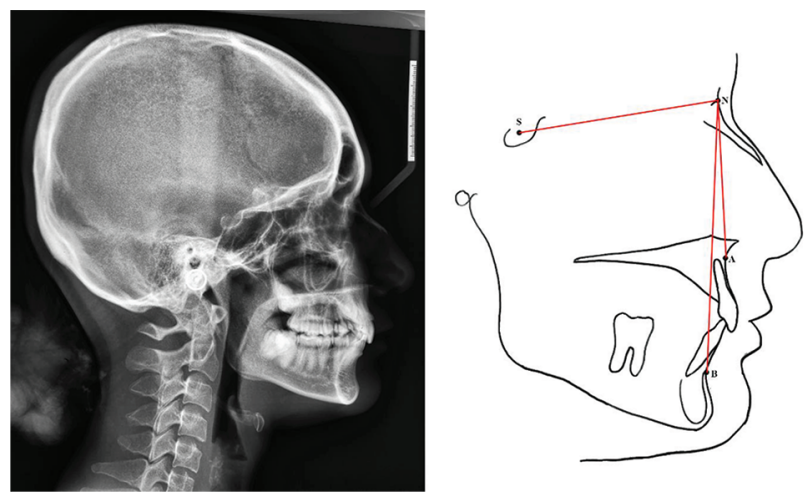

Fig. 2 Class I lateral cephalometric radiograph (on the left) and its cephalometric tracing as shown on the right side of the image. Lines are drawn between points $S, N$, and $A$ to get angle SNA, and between points $S, N$, and $B$ to get angle SNB. Angle ANB (2-4 degrees) is obtained by subtracting the value of SNB from SNA.
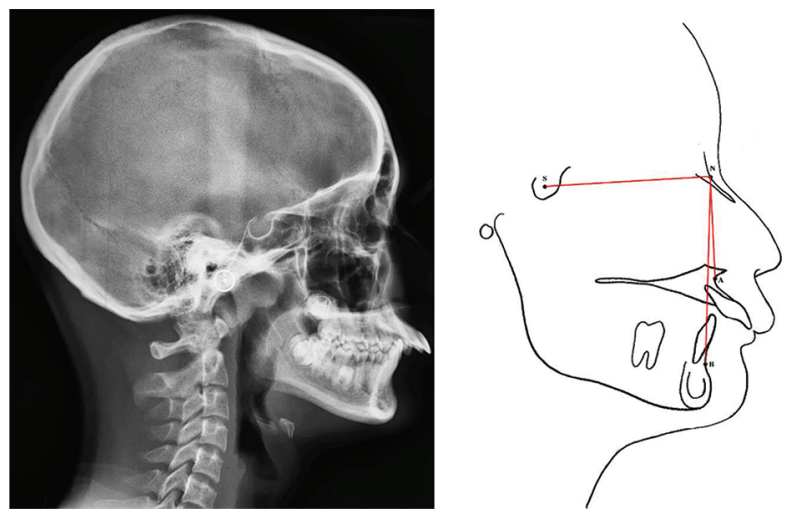

Fig. 3 Class II lateral cephalometric radiograph (on the left) and its cephalometric tracing as shown on the right side of the image. Lines are drawn between points $\mathrm{S}, \mathrm{N}$, and $\mathrm{A}$ to get angle SNA, and between points $S, N$, and $B$ to get angle SNB. Angle ANB ( $>4$ degrees) is obtained by subtracting the value of SNB from SNA.

\section{Cephalometric Analysis Criteria for Class III Facial Skeletal Pattern}

- Cephalometric analysis with value indicative of Class III based on Eastman analysis (ANB should be $<2$ degrees and SNB should be $>81$ degrees) as shown in - Fig. 4 .

- SNA within normal range indicative of average maxilla ( $81 \pm 3$ degrees).

- Negative Wits appraisal (AoBo) of $<-2 \mathrm{~mm}$.

- Concave facial profile.

\section{Saliva Collection}

Participants were required to fast from midnight until the saliva samples were taken at 8 a.m. (after 8 hours of fasting). Participants were also not allowed to brush in the morning prior to the appointment as to avoid the risk of gingival trauma/bleeding during sample collection. The saliva was then collected using the passive drooling and draining method. ${ }^{18}$ Participants were asked to expectorate into disposable tubes every 30 seconds over a period of 5 minutes. 

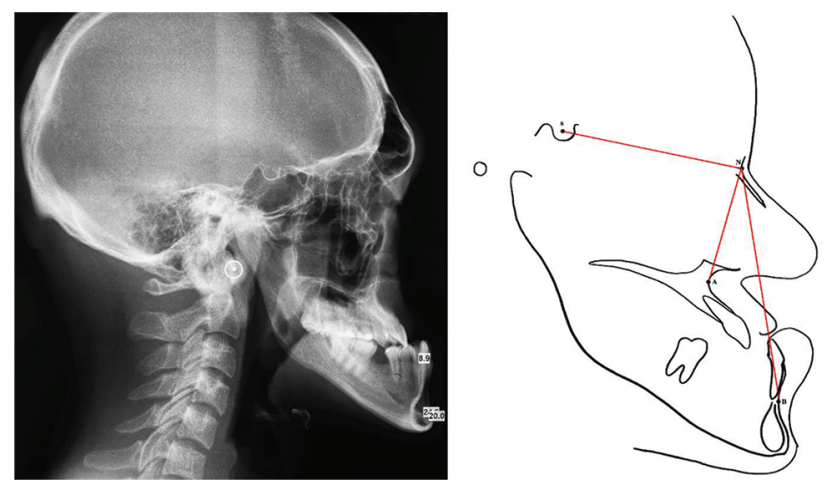

Fig. 4 Class III lateral cephalometric radiograph (on the left) and its cephalometric tracing as shown on the right side of the image. Lines are drawn between points $\mathrm{S}, \mathrm{N}$, and $\mathrm{A}$ to get angle SNA, and between points $S, N$, and $B$ to get angle SNB. Angle ANB ( $<2$ degrees) is obtained by subtracting the value of SNB from SNA.

Saliva was collected at the same time $(8$ a.m.) for all patients to eliminate differences in circadian rhythmicity as done in several previous studies. ${ }^{11,19,20}$ Samples were then centrifuged at $4,000 \times \mathrm{g} ; 10$ minutes and stored at $-25^{\circ} \mathrm{C}$.

\section{Leptin Analysis}

The saliva samples were then analyzed using a Human LEP (Leptin) enzyme-linked immunosorbent assay (ELISA) kit. The ELISA kit uses the Sandwich-ELISA principle whereby the relevant protein is stuck between two antibody molecules. This kit was chosen because Sandwich ELISAs have been reported to be two to five times more sensitive than all other ELISAs. ${ }^{21}$

The micro-ELISA plate provided in the kit has been precoated with antibody specific to Human LEP. Samples were added to the micro-ELISA plate wells and combined with the specific antibody. Then, a biotinylated detection antibody specific for Human LEP and Avidin horseradish peroxidase (HRP) conjugate were added successively to each microplate well and incubated. Free components were subsequently washed away, and the substrate solution was then added to each well. Wells that contain Human LEP, biotinylated detection antibody, and Avidin-HRP conjugate turned blue in color. The enzyme-substrate reaction is terminated by the addition of stop solution which then turns the color to yellow.

The optical density (OD) of the leptin was then measured with a microplate reader at a wavelength of $450 \mathrm{~nm}$. The OD value is proportional to the concentration of Human LEP.

\section{Results}

\section{Cephalometric Analysis}

The results of the cephalometric analysis are as shown in - Table 1.

\section{Human Leptin (LEP) Analysis \\ Salivary Leptin Hormone Levels in Different Facial Skeletal Patterns}

It was noted that the median levels of leptin hormone were higher in Class II and Class III skeletal patterns compared with the control group, Class I skeletal pattern as shown in - Fig. 5.

Salivary Leptin Hormone Level Comparison between the Facial Skeletal Pattern Classes

The Shapiro-Wilk normality test was run for the average Human Leptin (LEP) data for Class I, II, and III skeletal patterns. Kruskal-Wallis test was used as the data was overall not normally distributed (significance 0.000 ).

The results of the analysis indicate that there is a significant difference $(p<0.05)$ in the median levels of Human LEP between skeletal patterns, $\alpha(2, N=62)=11.802, p=0.003$, as shown in - Table 2.

Further tests were conducted to evaluate pairwise differences among the three groups. The results of these tests indicated a significant difference between the control group, Class I and the Class II group ( $p=0.004)$; and between the control group, Class I and the Class III group $(p=0.003)$. There was no significant difference reported between the Class II and Class III groups $(p=0.681)$.

Table 1 The mean values of the cephalometric variables

\begin{tabular}{|l|l|l|l|l|}
\hline \multicolumn{2}{|l|}{ Class } & I & II & III \\
\hline \multirow{2}{*}{ Sex } & Male & 9 & 11 & 7 \\
\cline { 2 - 5 } & Female & 15 & 12 & 8 \\
\hline Total & 24 & 23 & 15 \\
\hline Age (mean) & 23.75 & 24 & 25.2 \\
\hline SNA (degrees) & 81.71 & 83.83 & 79.83 \\
\hline SNB (degrees) & 78.79 & 77.30 & 81.27 \\
\hline ANB (degrees) & 2.92 & 6.43 & -1.43 \\
\hline Wits (AoBo) & -1.04 & 1.76 & -7.4 \\
\hline
\end{tabular}

Table 2 Comparison of median Optical density of participants according to skeletal pattern

\begin{tabular}{|l|l|l|l|}
\hline $\begin{array}{l}\text { Skeletal } \\
\text { pattern }\end{array}$ & $\begin{array}{l}\text { Median (IQR) Leptin } \\
\text { hormone level }\end{array}$ & $\begin{array}{l}\text { Chi square } \\
\text { statistic (df) }\end{array}$ & -Value \\
\hline Class I & $0.05255(0.0099)$ & \multirow{2}{*}{$11.802(2)$} & 0.003 \\
\hline Class II & $0.06125(0.0142)$ & & \\
\cline { 1 - 2 } Class III & $0.06185(0.0095)$ & & \\
\hline
\end{tabular}

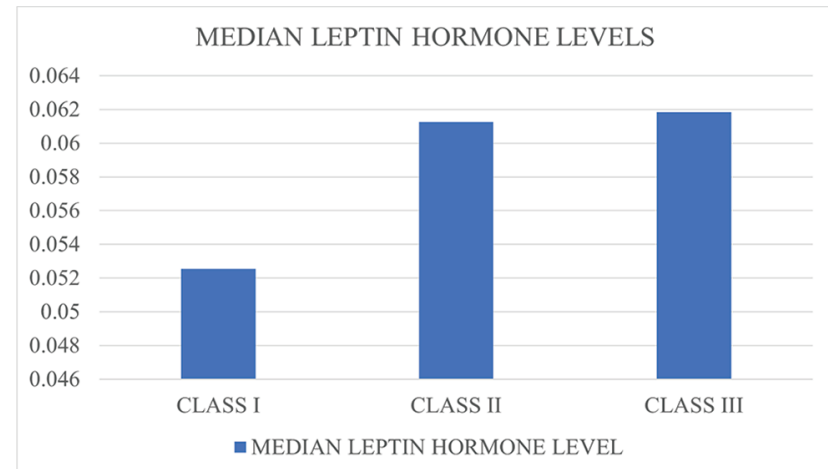

Fig. 5 The median levels of leptin hormone between Class I, II, and III facial skeletal patterns. 


\section{Discussion}

Cephalometric Analysis to Represent the Facial Pattern The lateral cephalometric analysis is commonly used as a diagnostic aid preorthodontic treatment as part of assessing the facial skeletal pattern. Skeletal pattern contributes significantly toward the etiology of various dental malocclusion. Various authors have recommended the use of both the ANB with the Eastman correction and Wits analysis for diagnosing and classifying the anteroposterior discrepancies of the skeletal base. ${ }^{22} \mathrm{As}$ it gives good representation of the craniofacial development and relation between the facial bones, it is used to classify the facial skeletal pattern in this study.

\section{Leptin and Its association with Facial Skeletal Pattern}

There have been no studies done in providing the evidence of salivary leptin hormone levels and its relationship with facial skeletal patterns. This prefatory study provides the preliminary data with intention to fill in the gap in the specific knowledge described above.

This study concluded that levels of salivary leptin hormone in Class II and Class III facial skeletal patterns were significantly higher compared with that of the control group which was the Class I or normal facial skeletal pattern.

The facial skeletal pattern is one of the major etiological factors contributing to dental malocclusion. The cranial base is a factor in determining the anteroposterior jaw relationship therefore influencing the occlusion of teeth. ${ }^{23} \mathrm{~A}$ systematic review by Almeida et al in $2017^{24}$ concluded that an increased cranial base angle can contribute to a Class II div I dental malocclusion. Conversely, a decreased cranial base angle is a contributory factor to the development of a Class III dental malocclusion due to mandibular prognathism..$^{25}$ The findings of this prefatory study may suggest the correlation between salivary leptin level with skeletal etiological factor such as mandibular prognathism/maxillary retrognathism/combination of both in the Class III skeletal pattern or mandibular retrognathism/maxillary prognathism/combination of both in the Class II skeletal pattern.

Since Class II and Class III is considered to be the part of the skeletal etiological factors contributing to malocclusion, the discovery of the association between leptin and this skeletal abnormality may be useful in prediction of growth in interceptive patients and as one of the diagnostic tools for adult patients.

Although some studies have associated higher leptin levels in females compared with males, ${ }^{26}$ as females have a higher body mass fat deposition, contradictory results have also been reported whereby no differences in salivary leptin levels were reported between males and females.20,27,28 This study does not differentiate the leptin levels according to gender as the main aim is to find the difference in varying facial skeletal patterns. There have been a few studies that have reported findings without discriminating the gender such as one done by Khorsand et $\mathrm{a}^{29}$ which looked at salivary leptin levels in healthy subjects and patients with periodontitis and another study by Purwar et $\mathrm{al}^{6}$ which evaluated the effects of periodontal therapy on serum and salivary leptin levels in chronic periodontitis patients with normal BMI.

As leptin exhibits circadian rhythmicity, ${ }^{26}$ where it can be at different levels throughout the day from the same patient, we tried to standardize this variable by taking all the sample at the same time (in the morning only).

Therefore, the author proposes that salivary leptin hormone could potentially be used as an indicator to detect Class II and Class III facial skeletal pattern in the future. This study also can be used in designing a larger study to further examine the role of leptin in specific facial basal bone including the maxilla and the mandible, to determine its contribution toward various facial deformity and dental malocclusion.

\section{Conclusion}

Salivary leptin hormone levels are higher in patients with Class II and Class III facial skeletal patterns compared with Class I.

\section{Ethical Approval}

Ethical approval was obtained from IIUM Research Ethics Committee (IREC) (REF NUMBER: IREC 2020-028). All investigations were performed in accordance with the principles embodied in the revised Declaration of Helsinki (2008). Consent was obtained prior to the experiment and the privacy of the human subjects was always guarded.

\section{Funding}

We would like to acknowledge the Ministry of Education and the International Islamic University Malaysia joint grant, FRGS RACER-19-030-0030 for funding this study.

\section{Conflict of Interest}

None declared.

\section{Acknowledgments}

We would also like to thank the staff of the Department of Orthodontics, Kulliyyah of Dentistry (IIUM), our research assistants, and staff of Central Research \& Animal Facility (CREAM) for their assistance.

\section{References}

1 Zhang Y, Chua S Jr. Leptin function and regulation. Compr Physiol 2017;8(1):351-369. Doi:10.1002/cphy.c160041

2 La Cava A. Leptin in inflammation and autoimmunity. Cytokine. 2017;98:51-58. Doi:10.1016/j.cyto.2016.10.011

3 Malik I, Durairajanayagam D, Singh H. Leptin and its actions on reproduction in males. Asian J Androl. 2019;21(3):296-299. Doi:10.4103/aja.aja_98_18

4 Reid IR, Baldock PA, Cornish J. Effects of Leptin on the Skeleton. Endocr Rev. 2018;39(6):938-959. doi:10.1210/er.2017-00226

5 La Cava A, Matarese G. The weight of leptin in immunity. Nat Rev Immunol 2004;4(5):371-379

6 Purwar P, Khan MA, Mahdi AA, et al. Salivary and serum leptin concentrations in patients with chronic periodontitis. J Periodontol 2015;86(4):588-594

7 Upadhyay J, Farr OM, Mantzoros CS. The role of leptin in regulating bone metabolism. Metabolism 2015;64(1):105-113 
8 Xu J-C, Wu G-H, Zhou L-L, Yang X-J, Liu J-T. Leptin improves osteoblast differentiation of human bone marrow stroma stem cells. Eur Rev Med Pharmacol Sci 2016;20(16):3507-3513

9 Zhang B, Yang L, Zeng Z, et al. Leptin potentiates BMP9-induced osteogenic differentiation of mesenchymal stem cells through the activation of JAK/STAT signaling. Stem Cells Dev 2020;29(8):498-510

10 Holloway WR, Collier FML, Aitken CJ, et al. Leptin inhibits osteoclast generation. J Bone Miner Res 2002;17(2):200-209

11 Bakar NA, Kamil W, Al Bayati L, Mustafa BE. Saliva leptin levels in tooth movement during initial stage of orthodontic alignment: a pilot study. Braz J Oral Sci 2017;16:1-8. Doi:10.20396/ bjos.v16i0.8651060

12 Yan B, Liu D, Zhang C, et al. Obesity attenuates force-induced tooth movement in mice with the elevation of leptin level: a preliminary translational study. Am J Transl Res 2018; 10(12):4107-4118

13 Srinivasan B, Chitharanjan A, Kailasam V, Lavu V, Ganapathy V. Evaluation of leptin concentration in Gingival Crevicular Fluid (GCF) during orthodontic tooth movement and its correlation to the rate of tooth movement. J Orthod Sci 2019;8(1):6

14 Shaw K, McIntyre G, Mossey P, Menhinick A, Thomson D. Validation of conventional 2D lateral cephalometry using 3D cone beam CT. J Orthod. 2013 Mar;40(1):22-28

15 Jacobson A. The "Wits" appraisal of jaw disharmony. 1975. Am J Orthod Dentofacial Orthop 2003;124(5):470-479

16 Oktay H. A comparison of ANB, WITS, AF-BF, and APDI measurements. Am J Orthod Dentofacial Orthop 1991;99(2):122-128

17 Barber SK, Littlewood SJ, Mitchell L. Cephalometrics. In: An Introduction to Orthodontics (5th Edition). Oxford University Press (OUP), United Kingdom; 2019:72-84

18 Bellagambi FG, Lomonaco T, Salvo P, et al. Saliva sampling: methods and devices. An overview. Trends Analyt Chem 2020;124(6):115781. Doi:12410.1016/j.trac.2019.115781

19 Kubala E, Strzelecka P, Grzegocka M, et al. A review of selected studies that determine the physical and chemical properties of saliva in the field of dental treatment. BioMed Res Int 2018;2018:6572381

20 Thanakun S, Watanabe H, Thaweboon S, Izumi Y. Comparison of salivary and plasma adiponectin and leptin in patients with metabolic syndrome. Diabetol Metab Syndr 2014;6(1):19

21 Aydin S. A short history, principles, and types of ELISA, and our laboratory experience with peptide/protein analyses using ELISA. Peptides 2015;72:4-15

22 Zamora N, Cibrián R, Gandia JL, Paredes V. Study between ANB angle and Wits appraisal in cone beam computed tomography (CBCT). Med Oral Patol Oral Cir Bucal 2013;18(4):e725-e732

23 Gong A, Li J, Wang Z, et al. Cranial base characteristics in anteroposterior malocclusions: a meta-analysis. Angle Orthod 2016;86(4):668-680

24 Almeida KCM, Raveli TB, Vieira CIV, Santos-Pinto AD, Raveli DB. Influence of the cranial base flexion on Class I, II and III malocclusions: a systematic review. Dental Press J Orthod 2017;22(5):56-66

25 Sanggarnjanavanich S, Sekiya T, Nomura Y, Nakayama T, Hanada N, Nakamura Y. Cranial-base morphology in adults with skeletal Class III malocclusion. Am J Orthod Dentofacial Orthop 2014;146(1):82-91

26 Randeva HS, Karteris E, Lewandowski KC, Sailesh S, O'Hare P, Hillhouse EW. Circadian rhythmicity of salivary leptin in healthy subjects. Mol Genet Metab 2003;78(3):229-235

27 Rodrigues L, Espanca R, Costa AR, et al. Association between salivary leptin levels and taste perception in children. J Nutr Metab 2017;2017:7260169

28 Idris A, Khamis AG, Ghazali NB, Steele M, Koh D, Tuah NA. Salivary leptin concentrations in Bruneian secondary school children. Asian Pac J Trop Biomed 2016;6(4):335-337

29 Khorsand A, Bayani M, Yaghobee S, Torabi S, Kharrazifard MJ, Mohammadnejhad F. Evaluation of salivary leptin levels in healthy subjects and patients with advanced periodontitis. J Dent (Tehran) 2016;13(1):1-9 